OPEN ACCESS

Edited by:

Erja Portegijs,

University of Jyväskylä, Finland

Reviewed by:

Erik Timmermans,

Amsterdam University Medical Center

(UMC), Netherlands

Caroline Diane Bergeron,

Public Health Agency of Canada

(PHAC), Canada

*Correspondence:

Xiaowu Lin

973742941@qq.com

Specialty section:

This article was submitted to

Aging and Public Health,

a section of the journal

Frontiers in Public Health

Received: 28 June 2020

Accepted: 02 October 2020

Published: 05 November 2020

Citation:

He H, Li T, Yu Y and Lin X (2020)

Associations Between Built

Environment Characteristics and

Walking in Older Adults in a

High-Density City: A Study From a

Chinese Megacity.

Front. Public Health 8:577140.

doi: 10.3389/fpubh.2020.577140

\section{Associations Between Built Environment Characteristics and Walking in Older Adults in a High-Density City: A Study From a Chinese Megacity}

\author{
Hui He ${ }^{1}$, Tingting $\mathrm{Li}^{1}$, Yanwei $\mathrm{Yu}^{1}$ and Xiaowu Lin ${ }^{2 *}$ \\ ${ }^{1}$ School of Architecture and Urban Planning, Huazhong University of Science and Technology, Wuhan, China, ${ }^{2}$ Xiamen \\ Urban Planning \& Design Institute, Xiamen, China
}

The built environment is an important factor affecting physical activity, especially walkability. Walkability is used to characterize the user friendliness of outdoor physical activity. However, studies on walkability and physical activity are mainly concentrated on low-density Western cities. Study on the walkability of high-density cities in Asia, especially with the elderly, is seriously lacking. And walkability is often used as a composite indicator. This study mainly re-examines the relationship between the common indicators of walkability (population density, street connectivity, land-use mix, and retail density), transport-related walking, and leisure-time walking with older adults in China's megacities. Twelve housing estates in Wuhan were selected for study areas. We explored the association between the walking activities of 1,161 elderly people ( $\geq 60$ years old) and the indicators of walkability in their neighborhoods. Socio-demographic characteristics were controlled in the multilevel logistic regression models of the built environment walking associations. We found that there was no significant correlation between the four indicators of walkability and transport-related walking. Street connectivity is significantly positively correlated with the participants' leisure-time walking (OR $=1.499,95 \% \mathrm{Cl}=1.068 \sim 2.103)$, and there was no significant correlation between the other indicator of walkability and leisure-time walking. The results show that there was no statistical correlation between walkability and transport-related walking in the elderly, and only one indicator was related to leisure-time walking. It is extremely important to re-examine the characteristics of built environments and elderly walking activities in high-density cities. Only by implementing effective intervention strategies in different urban backgrounds can cities move toward a more active and healthier path.

Keywords: high-density city, walking, transport-related walking, leisure-time walking, older adults, walkability 


\section{INTRODUCTION}

At present, the acceleration of population aging has become a common phenomenon in megacities around the world. How to deal with the negative impact of population aging is a serious challenge facing humanity. According to a report released by the World Health Organization (WHO), the elderly population will exceed that of children, and $80 \%$ of the elderly will live in developing countries by 2050 (1). Chinese population aging is much faster than many middle and low income countries, and China's population aging has two characteristics: on the one hand, the process is accelerating in recent years; on the other hand, the number will triple (402 million people) by 2040 (2). Under the current situation of global aging and the shortage of medical resources, encouraging older people to participate in physical activities to improve their health is of greater significance than clinical treatment. The World Health Organization encourages the elderly to participate in at least $150 \mathrm{~min}$ of aerobic physical activity every week to protect their health (3). Empirical studies have shown that regular and adequate levels of physical activity can provide mental and physical health benefits and can also reduce the risk of many chronic diseases $(4,5)$. Despite such obvious benefits of physical activity, a WHO global health survey found that the percentage of the population that meets the recommended amount of exercise is decreasing with age (6). In 2013, nearly 50\% (100 million) of older people in China experienced non-communicable diseases. According to the 2010 Chronic Disease Risk Factor Surveillance Survey, nearly 84\% of older people do not engage in regular physical activities. And there was a marked difference among older people in urban (24\%) compared to rural areas (7.1\%) (7). The combination of population aging and physical inactivity reduces the quality of life of older adults and increases the burden of health care. Therefore, from the perspective of public health, it is essential to explore the relevant factors that promote the physical activity of the elderly and propose effective intervention strategies.

Compared with people of other ages, the elderly are often physically impaired and generally do not commute. They often engage in outdoor activities in spaces near their residential area $(8,9)$, so the characteristics of the neighborhood environment can affect the physical activity of the elderly. It is essential to explore the relationship between built environment and physical activity of the elderly in order to guide the construction of agefriendly communities to promote physical activity of the elderly, which will help maintain good physical function of the elderly and thus prolong independent community life. In the theoretical study of social ecological models, the built environment is one of the most important factors affecting physical activity $(10,11)$. In a number of systematic reviews, the researchers determined that built environment characteristics are related to physical activity of the elderly, including walkability, overall access to destinations and services, land-use combinations, and a walk-friendly infrastructure $(12,13)$. Most research cites two definitions of measurement range of a neighborhood environment. One defines the buffer zone geographically (generally within a $1,000 \mathrm{~m}$ buffer zone around the participant's residence). A study from Hong Kong defined an $800 \mathrm{~m}$ circular buffer zone of the neighborhood (14), and a study from Seattle defined a $500 \mathrm{~m}$ circular buffer zone (15). Researchers generally use GIS tools to audit the environmental attributes of a buffer zone. The second way of defining a measurement range is from the home starting point of participants to a self-aware walking area of 10 to $20 \mathrm{~min}$ $(16,17)$. The general neighborhood environmental perception questionnaire is used to assess the environmental attributes.

The 3D (Density, Diversity, and Design) environmental elements have also been shown to relate to the physical activity of the elderly (especially walking activities) in land-use mix, population density, street connectivity, and retail facilities (1820). In the study of low-density cities in western developed countries, it was found that the above environmental factors are more positively related to the promotion of outdoor physical activities. Therefore, based on research results of the $3 \mathrm{D}$ elements, the researchers put forward a composite indicator of walkability that characterizes the degree of friendliness of the built environment to the physical activities of residents (21, 22). The combined indicators of walkability generally include residential density, street connectivity, land-use mix, and the retail building area ratio $(23,24)$. When calculating walking ability, the measured values are standardized and then weighted together $(25,26)$.

As mentioned earlier, relevant research between the indicators of walkability and physical activity is carried out frequently on low-density cities in the West, and most research results show that indicators of walkability promote residents' physical exercise. However, there are relatively few studies on highdensity cities in China, especially China's megacities. What is more, the population density of China's megacities is much higher than that of many cities in Western countries, and the differences between urban built environments and culture may result in different research results. Taking population density as an example, academic circles have found relevant research results in China's megacities: some research results show that it is negatively correlated with adolescents' entertainment physical activity $(27,28)$, or they show no correlation (29); another study found that it is negatively related to the leisure physical activities of adult women (30). Therefore, it is particularly important to re-examine the relationship between the built environment of megacities and the physical activity of residents. Research should focus on the elderly because the population aging degree in China's megacities is acute. It is critical to intervene in the health of the elderly from the aspect of built environment. The local government should promote the physical activity of the elderly from the aspects of planning policy and urban design, which can reduce the pressure of elderly care (31).

Related research shows that walking is the most popular physical activity for the elderly (32), so this study focuses on the relationship between elderly walking activities and the built environment. Two points need to be emphasized. First, the existing calculation formula of walkability is based on the fact that all indicators are positively correlated with physical activity, but some indicators of walkability may not be positively correlated with physical activity. Secondly, current research mainly studies the built environment from the perspective of a single type of physical activity, and there is a lack of comparison between 
different categories. In this study, however, the elderly walking activities are divided into transport-related walking and leisuretime walking, and we compare the differences of the relationship between built environment and two types of walking activities in the elderly.

In summary, this study examined the relationship between two types of walking and the walkability index of the elderly in 12 residential areas in Wuhan, China. We hypothesize that there are positive relationships between the four indicators of walkability and both types of walking based on the findings of previous studies.

\section{METHODS}

\section{Study Areas and Sampling Approach}

Wuhan is a megacity in central China (Figure 1A). The proportion of the aging population of Wuhan has been increasing in the past two decades, and the aging rate of 7 administrative districts located in the main urban area has exceeded $20 \%$ since 2018. The main urban area of Wuhan has a much higher aging rate than the suburban areas (Figure 1B) (33). The population density of the main urban area of Wuhan is $5,898 \sim 25,790$ people $/ \mathrm{km}^{2}$ (34), the minimum population density $\left(5,898\right.$ people $\left./ \mathrm{km}^{2}\right)$ in our study is still much higher than 500 persons $/ \mathrm{km}^{2}$, the cutoff for high residential density in Western countries (35). During the selection, we chose residential areas with a high aging rate so that the researchers could collect enough data. We also sought to select housing estates with similar homogeneous socioeconomic (SES) profiles; thus, we selected housing estates with a similar median house price. Based on those criteria, we selected 12 housing estates in the main urban area as our sample (Figure 1C).

We conducted the study from October to November 2019, when the weather is cool and pleasant for walking activities with older adults. Trained interviewers visited the selected housing estates and interviewed 80-120 older adults, using a random sampling method in each housing estate. All participants were able to engage in physical activity independently and had lived in the residence for over 1 year. A total of 1,161 valid questionnaires were collected.

\section{Walking Data}

The times the adults walked were obtained through questionnaire interviews. The content and form of the questionnaire were optimized based on the International Physical Activity Questionnaire. Because older adults may have difficulty reading or filling out the questionnaire, the survey was completed by trained interviewers after face-to-face interviews with participants. The survey mainly investigated the transportrelated walking activities and leisure-time walking activities of the elderly in the neighborhood. The following four questions were asked:

1. In the last 7 days, how many days have you carried out transport-related walking for at least 10 min (e.g., walking to the bus station, shopping, seeing a doctor, etc.)?
2. How much time do you usually spend walking in a day when you have transport-related walking?

3. In the last 7 days, how many days did you have a leisure-time walking activity that lasted for at least 10 min (excluding the transport-related walking activities mentioned in question 2)?

4. How much time do you usually spend a day on leisuretime walking?

We multiplied the average duration of walking time (in minutes) by the number of days engaged in walking in the past 7 days to obtain the total time of the two types of walking in older adults. As the total duration distribution of the two types of walking activities was highly skewed, with many participants reporting few transport-related walking (38.16\%), but much leisure-time walking $(66.93 \%)$ being reported, the total minutes of walking time per week was transformed into binary variables. We transformed transport-related walking into binary categorical variables of $\geq 150$ vs. $<150 \mathrm{~min} /$ per week [WHO recommends that the elderly exercise "150 min/week" to protect their health (3)], and we transformed leisure-time walking into binary categorical variables of $\geq 150$ vs. $<150 \mathrm{~min} /$ per week.

\section{Built Environment Variables}

The built environment variables select common indicators in walkability, including population density, street connectivity, land-use mix, and retail density. The measurement range of environment variables is within an $800 \mathrm{~m}$ circular buffer zone around the housing estate of participants. The selection of the $800 \mathrm{~m}$ buffer was based on average walking distance and it is the area within 10 to $15 \mathrm{~min}$ elderly walking distance. Population density is defined as the resident population per unit of land area where the participant is located. Street connectivity measures the inter-connectedness of the street network within a participant's walkable service area. The measure is a ratio of the count of three (or more) way intersections over the area $\left(\mathrm{km}^{2}\right)$. In the mixed land-use calculation, the land types are mainly divided into three categories: residential, commercial, and office (21); Retail business density measures the convenience of daily shopping within a participant's walkable service area. The four built environment variables are described along with applicable data sources in Table 1.

\section{Individual Covariances}

Individual covariates include gender, age, and education level; the participants' ages were transformed into a categorical variable with three levels: 60-69 years (reference category), 7079 years, and $\geq 80$ years. Education levels were transformed into a categorical variable with four levels: primary school and below (reference category), middle school, high school, and postsecondary school.

\section{Data Analysis}

In this study, 1,210 eligible participants were recruited, while 1,161 completed the survey (response rate $=96 \%$ ). Multilevel logistic regression models were conducted to investigate the relationship between the built environment and the two types of walking activities for older adults. The 


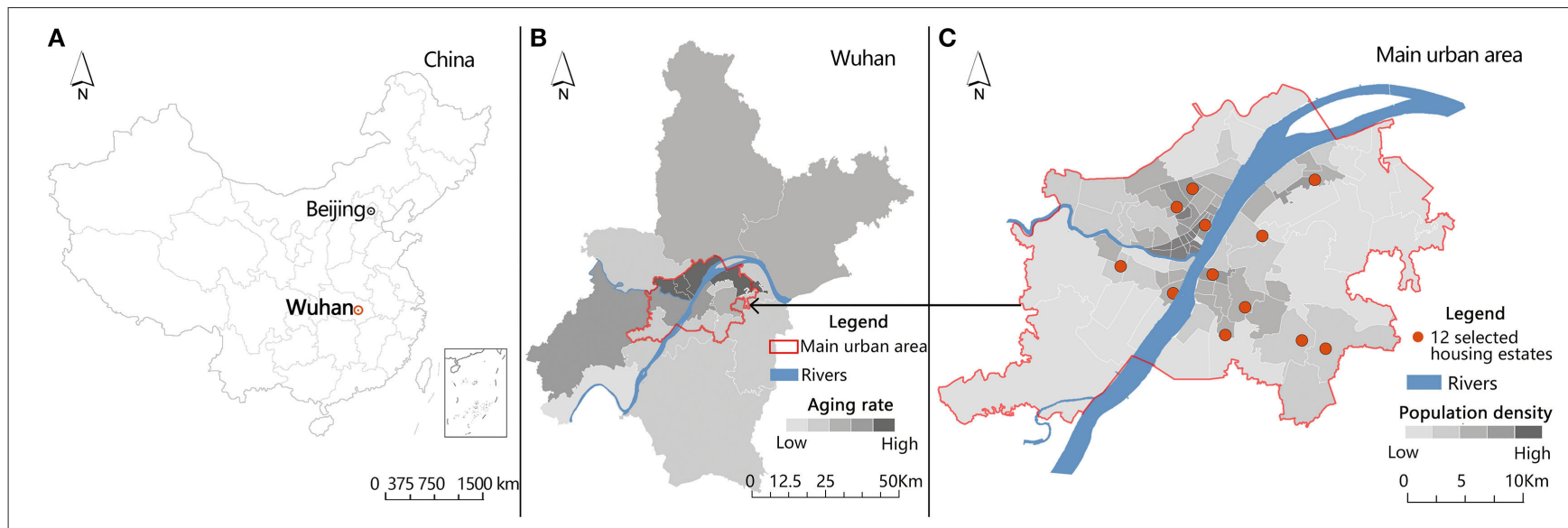

FIGURE 1 | (A) Location of Wuhan in China; (B) Proportion of the aging population in different administrative districts of Wuhan; and (C) The 12 selected housing estates in Wuhan.

TABLE 1 | Built environment measures.

\begin{tabular}{|c|c|c|c|c|}
\hline Measure & Definition & $\begin{array}{l}\text { Scale of measurement } \\
\text { for target area selection }\end{array}$ & Equation & Data source(s) \\
\hline Population density & Resident population per unit of land area & Administrative Street ${ }^{a}$ & $\begin{array}{l}\text { Count of resident population/area of } \\
\text { administrative Street }\end{array}$ & $\begin{array}{l}\text { The Sixth National Census } \\
\text { in Wuhan (2010) }\end{array}$ \\
\hline Street connectivity & $\begin{array}{l}\text { Number of street intersections per unit of land } \\
\text { area }\end{array}$ & 800 m circular buffer & $\begin{array}{l}\text { Number of intersections/area of } \\
800 \mathrm{~m} \text { circular buffer }\end{array}$ & $\begin{array}{l}\text { Baidu Maps (accessed } \\
\text { September 17, 2019) }\end{array}$ \\
\hline Land-use mix & $\begin{array}{l}\text { Evenness of distribution of residential, } \\
\text { commercial, and office per unit of land area }\end{array}$ & $800 \mathrm{~m}$ circular buffer & Equation below ${ }^{b}$ & $\begin{array}{l}\text { Urban Master Planning of } \\
\text { Wuhan (2010-2020) }\end{array}$ \\
\hline Retail density & Number of retail shops per unit of land area & $800 \mathrm{~m}$ circular buffer & $\begin{array}{l}\text { Number of retail shops/area of } 800 \mathrm{~m} \\
\text { circular buffer }\end{array}$ & $\begin{array}{l}\text { Amap (accessed } \\
\text { September 10, 2019) }\end{array}$ \\
\hline
\end{tabular}

${ }^{a}$ Administrative street is the smallest unit of urban population statistics in China.

b

$$
\text { land - use mix }=\frac{(-1) \times\left[\left(\frac{b 1}{a}\right) \times \ln \left(\frac{b 1}{a}\right)+\left(\frac{b 2}{a}\right) \times \ln \left(\frac{b 2}{a}\right)+\left(\frac{b 3}{a}\right) \times \ln \left(\frac{b 3}{a}\right)\right]}{\ln 3} .
$$

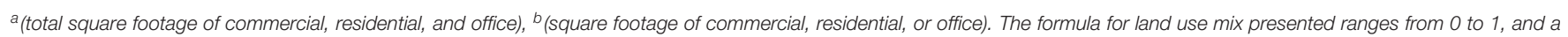
high score indicates high heterogeneity of land use.

house estates were assigned a random effect that accounts for the clustering in the physical activity of participants in the house estates. Model 1 included built environment variables, and Model 2 included further controlled individual covariates. All model analysis results reported Odds Ratios (ORs) and their $95 \%$ confidence intervals $(95 \% \mathrm{CI}$ ) and $p$ values. These analyses were conducted with $\mathrm{R}$ and a multilevel package lme4 (36).

\section{RESULTS}

The descriptive data are shown in Table 2. Approximately $38 \%$ of the participants performed at least $150 \mathrm{~min}$ of transport-related walking in a week; $\sim 67 \%$ of the participants performed at least 150 min of leisure-time walking in a week.

The results of the multilevel logistic regression model of the participants' transport-related walking time and built environment variables are shown in Table 3. The four indicators of walkability (population density, street connectivity, land-use mix, and retail density) were not significantly correlated with the likelihood of engaging in at least $150 \mathrm{~min}$ of transportrelated walking in Models $1 \& 2$. Among the individual covariates, age was significantly related to the likelihood of participating in transport-related walking for at least $150 \mathrm{~min}$. Participants over 70 years old were less likely to conduct transport-related walking than participants who were 60-69 years old ( $70-79$ years old: $\mathrm{OR}=0.561,95 \% \mathrm{CI}=0.423 \sim 0.745$; $\geq 80$ years old: $\mathrm{OR}=0.242,95 \% \mathrm{CI}=0.159 \sim 0.368$ ), and middle school education level was negatively associated with the likelihood of participating in transport-related walking for at least $150 \mathrm{~min}(\mathrm{OR}=0.684,95 \% \mathrm{CI}=0.490 \sim 0.954)$. Gender and other education levels had no significant association with the amount of transport-related walking. The direction and magnitude of the effect of built environment variables on transport-related walking time was similar across Model 1 and Model 2. 
TABLE 2 | Descriptive information for participants' walking data, socio-demographic characteristics, and built environment variables.

\begin{tabular}{lc}
\hline Variables & Mean (SD)/\% \\
\hline Outcome $(N=1,161)$ & $38.16 \%$ \\
Transport-related walking, $\% \geq 150$ min & $66.93 \%$ \\
Leisure-time walking, $\% \geq 150$ min & \\
Socio-demographic variables $(N=1,161)$ & 71.22 \\
Age & $46.43 \%$ \\
Gender, $\%$ male & \\
Education level & $36.86 \%$ \\
Primary school and below & $26.79 \%$ \\
Middle school & $15.76 \%$ \\
High school & $20.59 \%$ \\
Postsecondary school & \\
Built environment factors $(N=12)$ & \\
Population density $\left(\right.$ person $\left./ \mathrm{km}^{2}\right)$ & $25539.00(10868.01)$ \\
Street intersection density $\left(\# / \mathrm{km}^{2}\right)$ & $15.00(10.69)$ \\
Land-use mix & $0.60(0.16)$ \\
Number of retail shops $\left(\# / \mathrm{km}^{2}\right)$ & $423.00(233.81)$ \\
\hline
\end{tabular}

The results of the multilevel logistic regression model of the participants' leisure-time walking time and built environment variables are shown in Table 4 . Street connectivity was positively correlated $(\mathrm{OR}=1.516,95 \% \mathrm{CI}=1.083 \sim 2.123$ in Model $1 ; \mathrm{OR}=1.499,95 \% \mathrm{CI}=1.068 \sim 2.103$ in Model 2) with the likelihood of participating in a minimum of $150 \mathrm{~min}$ of leisure-time walking, and participants exposed to a high street connectivity were significantly more likely to perform regular leisure-time walking. There was no significant correlation between the other three indicators (population density, landuse mix, and retail density) and the likelihood of participating in a minimum of $150 \mathrm{~min}$ of leisure-time walking. Among the individual covariates, postsecondary school education level was negatively associated with the likelihood of participating in leisure-time walking for at least $150 \mathrm{~min}(\mathrm{OR}=0.649,95 \%$ $\mathrm{CI}=0.453 \sim 0.929)$. Gender, age, and other education levels were not significantly related to the possibility of participating in leisure-time walking for at least $150 \mathrm{~min}$ a week. The direction and magnitude of the effect of built environment variables on leisure-time walking time was similar across both models.

\section{DISCUSSION}

\section{Major Findings}

This study further promotes the development of the content of healthy physical activity from two aspects. First, previous research has mainly focused on cities with low- and mediumdensity populations in the West. This study for a relatively large sample size focused on Wuhan, a megalopolis with a highdensity population that has not been previously studied. Second, this study specifically subdivides elderly walking activities into transport-related walking and leisure-time walking so that the different effects of walkability indicators on the different types of walking activities can be showed. The results of this study show that the associations of walkability factors and two types of walking activities are weaker or insignificant in high-density city.

We found leisure-time walking time only related to street connectivity. In this study, street connectivity is positively related to elderly leisure-time walking. Previous studies have shown that streets are the main public space for residents' leisure activities $(37,38)$. More street intersections provide the elderly with more path options for leisure-time walking, and the elderly choose streets with better space quality for walking activities. There is no significant correlation between population density, land use combination, retail business density and leisure-time walking among the elderly. Some studies have reported the correlation between walkability indicators and leisure-time walking among adults (39). The reason for the differences in the results may be that older adults have relatively more discretionary time to make better use of the relatively good environment around them compared with young people. There may also be another reason that these factors may affect the frequency of walking rather than the time of walking (40).

In our results, we found no significant correlation between transport-related walking time and the four indicators of walkability. According to informal Interviews, old adults have some negative comments on environmental attributes, with respondents citing reasons for not going out, such as too many road cars and speed on the road too fast. These traffic problems may be due to the over-dwelling population leading to increased motor vehicle use in the neighborhood (41). However, the result of our study shows that there is no significant correlation between transport-related walking time and the four indicators of walkability in the elderly, which is similar to the results of a recent study in China (42). The reason may be that for the elderly in Chinese cities, these venues often play an important role in housekeeping during their later years of life, helping families to shop, transport grandchildren to and from school, and accompany grandchildren to outdoor leisure and entertainment activities. Their travel purpose is clear, and these activities belong to the necessary activities of a family, even the old adults are not satisfied with the environment, they also need to travel on a regular basis. This also explains why transport-related walking is related to age. Older people are less likely to undertake outdoor family activities, so older people have less transportrelated walking.

Different from the western studies that showed a positive correlation between the indicators of walkability and physical activity, in this study, we found largely non-significant correlations between older adults' walking behaviors and objectively measured built environment factors in walkability. Recent studies conducted in other high-density cities also find these factors tend to be insignificant (14). Therefore, further studies are needed to examine the relationship between factors of walkability and walking for older adults in cities with different urban density. At the same time, some studies in China have shown that population density was negatively correlated with the two types of walking activities (41), but the existing calculation formula of walkability is based on the fact that all indicators are 
TABLE 3 | Logistic regression of built environment and achieving $\geq 150 \mathrm{~min}$ of transport-related walking a week.

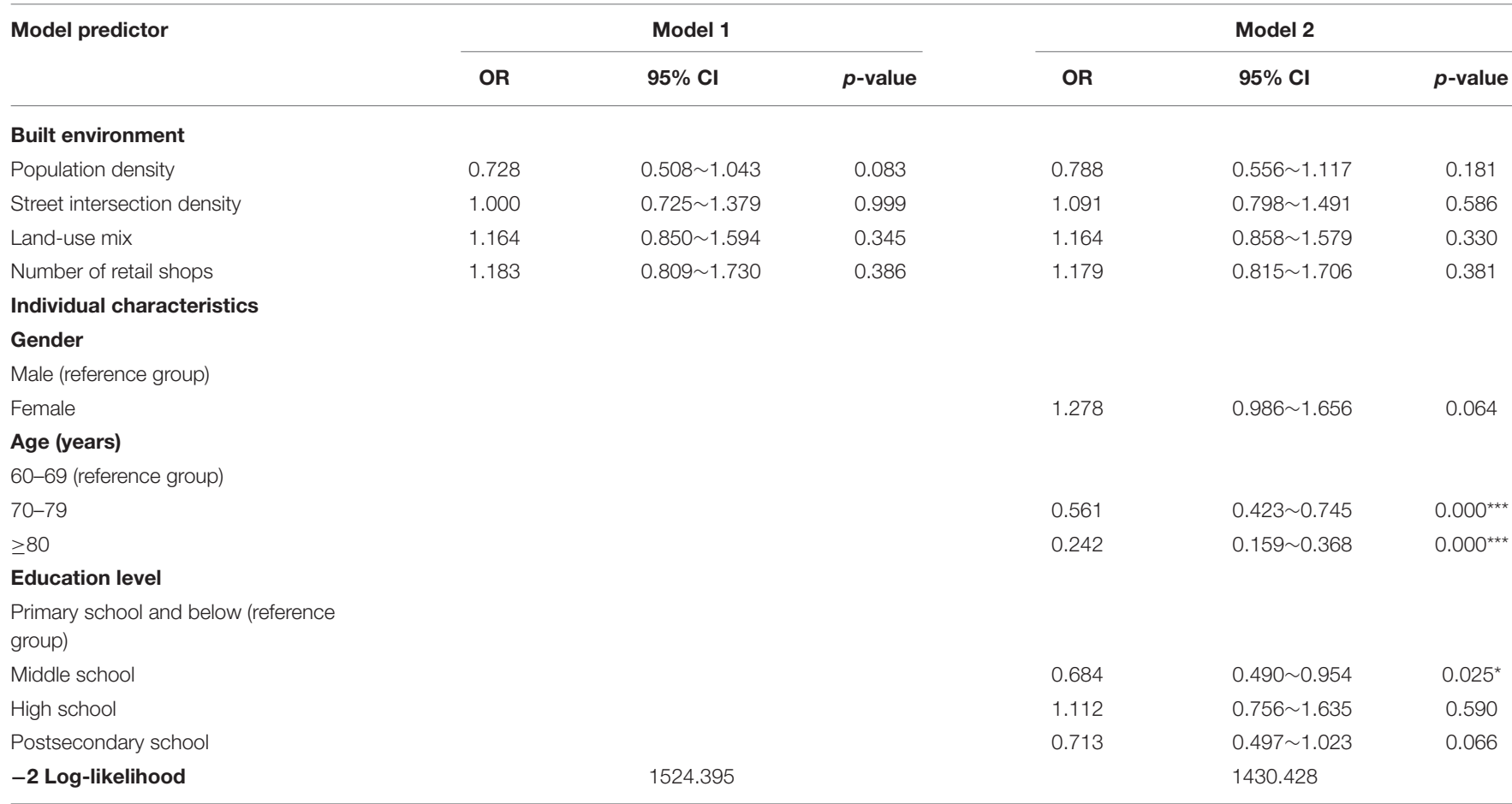

${ }^{*}<0.05 ;{ }^{* *}<0.01 ;{ }^{* * *}<0.001$.

TABLE 4 | Logistic regression of built environment and achieving $\geq 150 \mathrm{~min}$ of leisure-time walking a week.

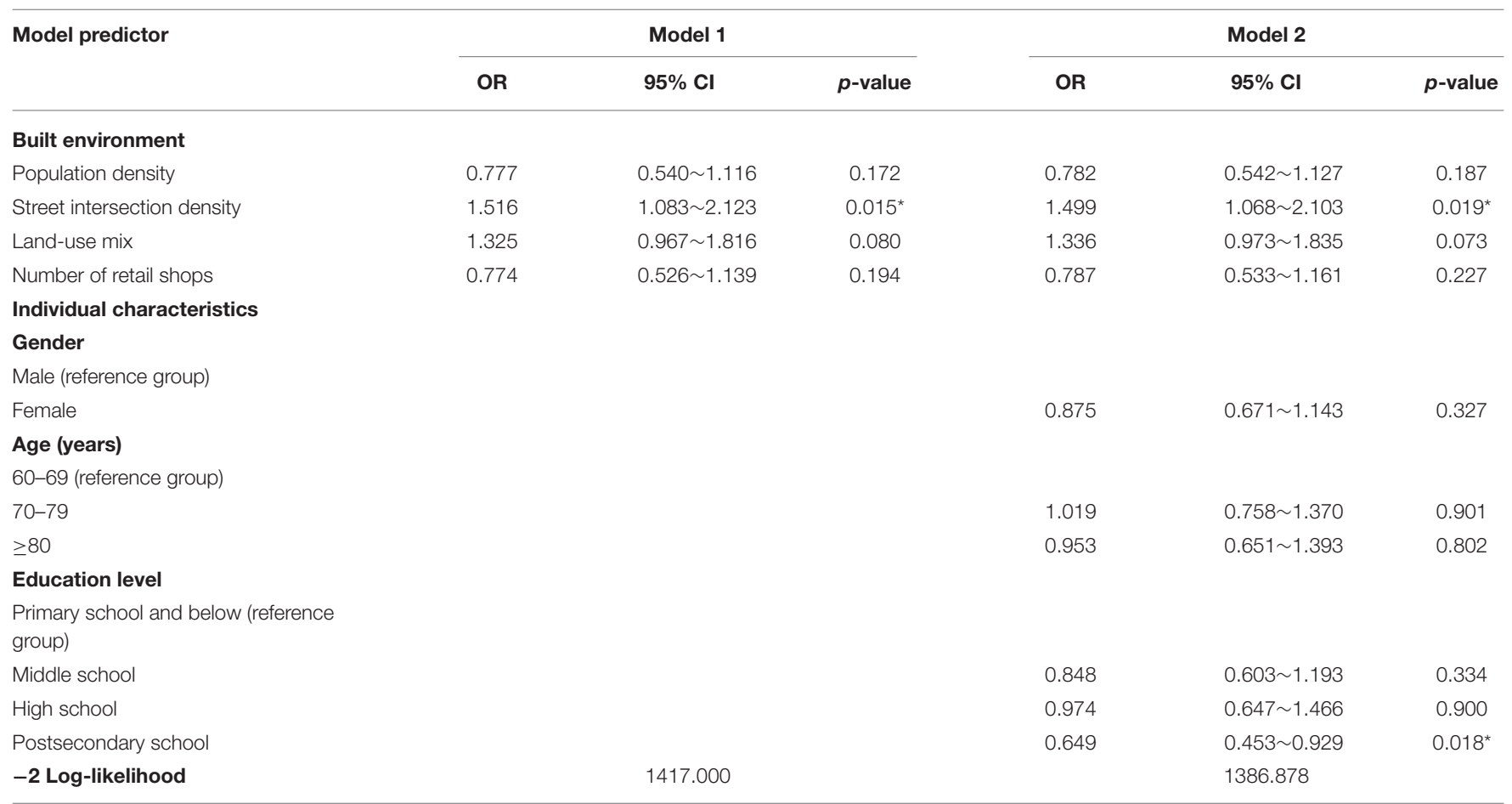

${ }^{*}<0.05 ;{ }^{* *}<0.01 ;{ }^{* * *}<0.001$.

positively correlated with physical activity $(43,44)$ therefore, the formula may need further study to improve the applicability of walkability.
In addition to the factors we studied, air pollution, traffic noise, traffic safety and crime may also affect older people's walking. There have been a lot of studies on these factors in 
Western countries (12), but there are still few in China. The built environment and social conditions among countries are greatly different. It is also of great value to study the correlation between these factors and walking among the elderly in China's cities and villages. China's air quality has improved so much since the eco-civilization strategy was introduced. Most people would hardly notice small changes in air quality. But older people with respiratory problems may be more likely to notice. In China, the relationship between traffic noise and walking in the elderly also was rarely studied. For China, such a high population density, crowded traffic countries, it is particularly important to figure out the associations between traffic noise, traffic congestion and elderly walking in order to better provide information for the construction of elderly friendly communities. In China, traffic safety always be mentioned, but there was little mention of crime, which may have something to do with the fact that there are so many people on the streets in China, and there is more surveillance to keep pedestrians safe. However, the large number of vehicles and fast speed were a big safety hazard.

A number of existing studies relied mainly on objective measurements, but there is no consensus on what defines a "neighborhood" (e.g., shape or size). Some studies have reported that the scale and shape of buffers can have an impact on study results (45). However, the use of different buffer radii did not alter the observed relationship in the two studies $(46,47)$. At the same time, some studies have begun to explore the impact of neighborhood buffer size across various adult life stages (48). However, little attention is focused on the buffer zones of these two types of walking may also differ.

\section{Limitations}

This study has several limitations. First, the cross-sectional research design cannot explain the causal relationship between the high-density urban built environment and elderly walking activities. Second, all measured built environment variables were collected using a single buffer size, and there was a lack of comparison of multiple buffer measurement results. The observed correlation may vary depending on the buffer size, and the range of participants' walking activities may exceed the buffer range. Thirdly, although this study included data on 1,161 individuals, it included only 12 housing estates. This might have affected the power for finding statistically significant associations between environmental attributes and two types of walking. To avoid such a problem, it may be necessary to select more housing estates with each housing estate still including a reasonable number of individuals (49). Finally, the study was conducted in a

\section{REFERENCES}

1. World Health Organization. Global Age-Friendly Cities: A Guide. (2007). Available online at: https://www.who.int/ageing/age_friendly_cities_guide/ en/ (accessed August 22, 2019).

2. World Health Organization. China Country Assessment Report on Ageing and Health. (2016). Available online at: https://www.who.int/ageing/publications/ china-country-assessment/en/ (accessed August 22, 2019). high-density city in China; and in order to verify the reliability of the results, more evidence from other high-density cities is needed.

\section{CONCLUSION}

This study examines the relationship between the characteristics of the built environment of high-density cities and the walking activities of the elderly in Wuhan. After emphasizing the different built environmental characteristics and the background of cultural life, it is obvious that the composite indicator of walkability needs to be revised to increase its applicability. Furthermore, the evidence provided by this study will help to clarify the various influential factors that affect the walking activity of the elderly in China's megacities, thereby helping to provide optimized strategies for the healthy development of elderly city residents.

\section{DATA AVAILABILITY STATEMENT}

The datasets presented in this article are not readily available because the dataset is a part of the project "Intelligent Recognition of Street Space Quality and its Planning Application: a Case Study of Wuhan" funded by the National Natural Science Foundation of China, 2020.01-2023.12. So the dataset is confidential during this period. Requests to access the datasets should be directed to Xiaowu Lin,973742941@qq.com.

\section{ETHICS STATEMENT}

Ethical review and approval was not required for the study on human participants in accordance with the local legislation and institutional requirements. The patients/participants provided their written informed consent to participate in this study.

\section{AUTHOR CONTRIBUTIONS}

$\mathrm{HH}$ conceived of the study, and participated in its design and coordination. XL and TL led the manuscript preparation. $\mathrm{XL}$ contributed to data collection and analysis. TL and YY contributed to data collection. All authors read, contributed to, and approved the final manuscript.

\section{FUNDING}

This study was funded by the National Natural Science Foundation of China (Grant No. 51978300).
3. World Health Organization. Global Recommendations on Physical Activity for Health. (2010). Available online at: https://www.who.int/dietphysicalactivity/ factsheet_recommendations/en/ (accessed August 22, 2019).

4. Warburton DER, Nicol CW, Bredin SSD. Health benefits of physical activity: the evidence. Can Med Assoc J. (2006) 174:801-9. doi: 10.1503/cmaj.051351

5. Bauman AE. Updating the evidence that physical activity is good for health: an epidemiological review 2000-2003. J Sci Med Sport. (2004) 7:619. doi: $10.1016 /$ S1440-2440(04)80273-1 
6. World Health Organization. World Report on Ageing and Health. (2015). Available online at: https://www.who.int/ageing/publications/world-report2015/en/ (accessed August 22, 2019).

7. World Health Organization. China Country Assessment Report on Ageing and Health. (2015). Available online at: https://www.who.int/ageing/publications/ china-country-assessment/en/ (accessed August 12, 2020).

8. Barnes LL, Wilson RS, Bienias JL, Mendes de Leon CF, Nicole Kim H-j, Buchman AS, et al. Correlates of life space in a volunteer cohort of older adults. Exp Aging Res. (2007) 33:77-93. doi: 10.1080/03610730601006420

9. Huang JZ, Zhang RQ, Hu GY. A research of the elderly's daily life circle based on spatial-temporal behavior-analysis of place recognition and spatial features. Urban Planning Forum. (2019) 03:87-95. doi: 10.16361/j.upf.201903011

10. Stokols D. Establishing and maintaining healthy environments: toward a social ecology of health promotion. Am Psychol. (1992) 47:6-22. doi: 10.1037/0003-066X.47.1.6

11. Sallis JF, Cervero RB, Ascher W, Henderson KA, Katherine Kraft M, Kerr J. An ecological approach to creating active living communities. Annu Rev Public Health. (2006) 27:297-322. doi: 10.1146/annurev.publhealth.27.021405.102100

12. Barnett DW, Barnett A, Nathan A, van Cauwenberg J, Cerin E. Built environmental correlates of older adults' total physical activity and walking: a systematic review and meta-analysis. Int J Behav Nutr Phys Act. (2017) 14:103. doi: 10.1186/s12966-017-0558-z

13. Cerin E, Nathan A, van Cauwenberg J, Barnett DW, Barnett A. The neighbourhood physical environment and active travel in older adults: a systematic review and meta-analysis. Int J Behav Nutr Phys Act. (2017) 14:1-23. doi: 10.1186/s12966-017-0471-5

14. Yang YY, He DS, Gou ZH, Wang RY, Liu Y, Lu Y. Association between street greenery and walking behavior in older adults in Hong Kong. Sust Cities Soc. (2019) 51:101747. doi: 10.1016/j.scs.2019.101747

15. Carlson JA, Sallis JF, Conway TL, Saelens BE, Frank LD, Kerr J, et al. Interactions between psychosocial and built environment factors in explaining older adults' physical activity. Prev Med. (2012) 54:6873. doi: 10.1016/j.ypmed.2011.10.004

16. Barnett A, Cerin E, Zhang CJP, Sit CHP, Johnston JM, Cheung MMC, et al. Associations between the neighbourhood environment characteristics and physical activity in older adults with specific types of chronic conditions: the ALECS cross-sectional study. Int J Behav Nutr Phys Act. (2016) 13:53. doi: 10.1186/s12966-016-0377-7

17. Inoue S, Ohya Y, Odagiri Y, Takamiya T, Kamada M, Okada S, et al. Perceived neighborhood environment and walking for specific purposes among elderly japanese. J Epidemiol. (2011) 21:481-90. doi: 10.2188/jea.JE20110044

18. Brownson RC, Hoehner CM, Day K, Forsyth A, Sallis JF. Measuring the built environment for physical activity: state of the science. Am J Prev Med. (2009) 36:S99-123. e12. doi: 10.1016/j.amepre.2009.01.005

19. McCormack GR, Shiell A. In search of causality: a systematic review of the relationship between the built environment and physical activity among adults. Int J Behav Nutr Phys Act. (2011) 8:125. doi: 10.1186/1479-5868-8-125

20. Koh PP, Wong YD. Comparing pedestrians' needs and behaviours in different land use environments. J Transp Geogr. (2013) 26:4350. doi: 10.1016/j.jtrangeo.2012.08.012

21. Frank LD, Andresen MA, Schmid TL. Obesity relationships with community design, physical activity, and time spent in cars. Am J Prev Med. (2004) 27:87-96. doi: 10.1016/j.amepre.2004.04.011

22. Frank LD. Public health and the built environment: emerging evidence and complexity. Can J Diet Pract Res. (2004) 65:1-4. Available online at: https:// search.proquest.com/docview/220825016/fulltext/619807A10296432FPQ/1? accountid $=11524$

23. Frank L, Kerr J, Rosenberg D, King A. Healthy aging and where you live: community design relationships with physical activity and body weight in older Americans. J Phys Act Health. (2010) 7:S8290. doi: 10.1123/jpah.7.s1.s82

24. King AC, Sallis JF, Frank LD, Saelens BE, Cain K, Conway TL, et al. Aging in neighborhoods differing in walkability and income: associations with physical activity and obesity in older adults. Soc Sci Med. (2011) 73:1525-33. doi: 10.1016/j.socscimed.2011. 08.032
25. Frank LD, Sallis JF, Conway TL, Chapman JE, Saelens BE, Bachman W. Many pathways from land use to health: associations between neighborhood walkability and active transportation, body mass index, and air quality. $J \mathrm{Am}$ Plann Assoc. (2006) 72:75-87. doi: 10.1080/01944360608976725

26. Frank LD, Saelens BE, Powell KE, Chapman JE. Stepping towards causation: do built environments or neighborhood and travel preferences explain physical activity, driving, and obesity? Soc Sci Med. (2007) 65:1898914. doi: 10.1016/j.socscimed.2007.05.053

27. Xu F, Li JQ, Liang YQ, Wang ZY, Hong X, Ware RS, et al. Associations of residential density with adolescents' physical activity in a rapidly urbanizing area of Mainland China. J Urban Health. (2010) 87:4453. doi: 10.1007/s11524-009-9409-9

28. An RP, Shen J, Yang QY, Yang Y. Impact of built environment on physical activity and obesity among children and adolescents in China: a narrative systematic review. J Sport Health Sci. (2019) 8:15369. doi: 10.1016/j.jshs.2018.11.003

29. Lin CW, Han XL, Fan J. Impacts of land development intensity on children's outdoor physical activities: a case study of shenzhen. City Plann Rev. (2018) 42:97-102. doi: 10.11819/cpr20181112a

30. Su M, Tan Yy, Liu Qm, Ren Yj, Kawachi I, Li Lm, et al. Association between perceived urban built environment attributes and leisure-time physical activity among adults in Hangzhou, China. Prev Med. (2014) 66:604. doi: 10.1016/j.ypmed.2014.06.001

31. Vogel T, Brechat PH, Leprêtre PM, Kaltenbach G, Berthel M, Lonsdorfer J. Health benefits of physical activity in older patients: a review. Int J Clin Pract. (2009) 63:303-20. doi: 10.1111/j.1742-1241.2008.01957.x

32. Cunningham GO, Michael YL. Concepts guiding the study of the impact of the built environment on physical activity for older adults: a review of the literature. Am J Health Promot. (2004) 18:435-43. doi: 10.4278/0890-1171-18.6.435

33. Civil Administration Burea of Wuhan. An Analysis of the form of Population Aging in Wuhan in 2018. (2019). Available online at: http://mzj.wuhan.gov. cn/zwgk_918/fdzdgk/gysyjs/shfl/201901/t20190125_1000644.shtml (accessed September 5, 2019).

34. Statistics Department of Hubei province. 2018 Wuhan Statistical Yearbook. (2019). Available online at: http://tjj.hubei.gov.cn/tjsj/sjkscx/tjnj/gsztj/whs/ 201911/P020191104653356795480.pdf (accessed September 5, 2019).

35. Alexander FE, Boyle P, Carli PM, Coebergh JW, Ekbom A, Levi F, et al Population density and childhood leukaemia: results of the EUROCLUS study. Eur J Cancer. (1999) 35:439-44. doi: 10.1016/S0959-8049(9 8)00385-2

36. Vienna, Austria: $\mathrm{R}$ Foundation for Statistical Computing 2014. $R$ : A language and environment for statistical computing. (2014). Available online at: http:// www.R-project.org (accessed September 8, 2020).

37. Giles-Corti B, Donovan RJ. The relative influence of individual, social and physical environment determinants of physical activity. Soc Sci Med. (2002) 54:1793-812. doi: 10.1016/S0277-9536(01)00150-2

38. Huston SL, Evenson KR, Bors P, Gizlice Z. Neighborhood environment, access to places for activity, and leisure-time physical activity in a diverse North Carolina population. Am J Health Promot. (2003) 18:5869. doi: 10.4278/0890-1171-18.1.58

39. Siqueira Reis R, Hino AAF, Ricardo Rech C, Kerr J, Curi Hallal P. Walkability and physical activity: findings from Curitiba, Brazil. Am J Prev Med. (2013) 45:269-75. doi: 10.1016/j.amepre.2013.04.020

40. Owen N, Cerin E, Leslie E, duToit L, Coffee N, Frank LD, et al. Neighborhood walkability and the walking behavior of Australian adults. Am J Prev Med. (2007) 33:387-95. doi: 10.1016/j.amepre.2007.07.025

41. Wang ZY, Qin ZZ, He J, Ma YY, Ye Q, Xiong YQ, et al. The association between residential density and physical activity among urban adults in regional China. BMC Public Health. (2019) 19:1279. doi: 10.1186/s12889-019-7593-4

42. Lu Y, Xiao Y, Ye Y. Urban density, diversity and design: Is more always better for walking? A study from Hong Kong. Prev Med. (2017) 103:S99-S103. doi: 10.1016/j.ypmed.2016.08.042

43. Frank LD, Sallis JF, Saelens BE, Leary L, Cain K, Conway TL, et al The development of a walkability index: application to the neighborhood quality of life study. Br J Sports Med. (2010) 44:924. doi: 10.1136/bjsm.2009. 058701 
44. Peiravian F, Derrible S, Ijaz F. Development and application of the pedestrian environment index (PEI). J Transp Geogr. (2014) 39:7384. doi: 10.1016/j.jtrangeo.2014.06.020

45. James P, Berrigan D, Hart JE, Aaron Hipp J, Hipp A, Kerr J, et al. Effects of buffer size and shape on associations between the built environment and energy balance. Health Place. (2014) 27:162-1170. doi: 10.1016/j.healthplace.2014.02.003

46. Nagel CL, Carlson NE, Bosworth M, Michael YL. The relation between neighborhood built environment and walking activity among older adults. Am J Epidemiol. (2008) 168:461-8. doi: 10.1093/aje/ kwn158

47. Berke EM, Koepsell TD, Vernez Moudon A, Hoskins RE, Larson EB. Association of the built environment with physical activity and obesity in older persons. Am J Public Health. (2007) 97:486-92. doi: 10.2105/AJPH.2006.085837

48. Villanueva K, Knuiman M, Nathan A, Giles-Corti B, Christian H, Foster S, et al. The impact of neighborhood walkability on walking: does it differ across adult life stage and does neighborhood buffer size matter? Health Place. (2014) 25:43-6. doi: 10.1016/j.healthplace.2013.10.005

49. Wendel-Vos GCW, van Hooijdonk C, Uitenbroek D, Agyemang C, Lindeman EM, Droomers M. Environmental attributes related to walking and bicycling at the individual and contextual level. J Epidemiol Community Health. (2008) 62:689. doi: $10.1136 /$ jech.2007.062869

Conflict of Interest: The authors declare that the research was conducted in the absence of any commercial or financial relationships that could be construed as a potential conflict of interest.

Copyright (c) $2020 \mathrm{He}, \mathrm{Li}, \mathrm{Yu}$ and Lin. This is an open-access article distributed under the terms of the Creative Commons Attribution License (CC BY). The use, distribution or reproduction in other forums is permitted, provided the original author(s) and the copyright owner(s) are credited and that the original publication in this journal is cited, in accordance with accepted academic practice. No use, distribution or reproduction is permitted which does not comply with these terms. 